\title{
HUBUNGAN ANTARA DEMOGRAFI KONSUMEN DENGAN KEPUASAN TERHADAP LAYANAN PAKET PERAWATAN SPA DI GY SPA JAKARTA
}

\author{
Hera Oktadiana ${ }^{1}$; Yuliana ${ }^{2}$ \\ ${ }^{1,2}$ Hotel Manajemen, Fakultas Ekonomi dan Bisnis, Universitas Bina Nusantara \\ Jln. K.H. Syahdan No. 9, Palmerah, Jakarta Barat 11480 \\ yulicks_boss@hotmail.com
}

\begin{abstract}
Spa industry has been growing quite fast in many parts of the world, including Indonesia. The prospect of spa business is still very positive and wide open. There are many varieties of spas offered, such as day spas, hotel-based spas, resort spas and destination spas. Regardless of the type of spa, most spa operators provide massage and nutrition related services. GY Spa, one of the best spa operators in Jakarta offers several spa packages which include body massage, body treatment, body scrub, face massage and aromatheraphy. This research aims to find the correlation between the demographic segmentation and the consumer satisfaction towards the spa packages in GY Spa. Based on the research, it is found that education, occupation and nationality have no correlation toward the consumer satisfaction, while age and gender shown to have correlation. Female and the younger customers are more satisfied with the spa packages offered by GY Spa.
\end{abstract}

Keywords: spa, consumer demographic, service satisfaction

\begin{abstract}
ABSTRAK
Industri spa telah berkembang cukup cepat di berbagai belahan dunia, termasuk Indonesia. Prospek bisnis spa masih sangat positif dan terbuka lebar. Ada banyak jenis spa yang ditawarkan seperti day spas, hotelbased spas, resort spas dan destination spas. Terlepas dari jenis spa, kebanyakan pelayanan spa memberikan layanan pijat dan gizi terkait. GY Spa, salah satu operator spa terbaik di Jakarta menawarkan beberapa paket spa yang meliputi pijat tubuh, perawatan tubuh, body scrub, pijat wajah, dan aromaterapi. Penelitian ini bertujuan untuk mengetahui hubungan antara segmentasi demografi dan kepuasan konsumen terhadap paketpaket spa di Spa GY. Berdasarkan penelitian, ditemukan bahwa pendidikan, pekerjaan dan kebangsaan tidak memiliki hubungan terhadap kepuasan konsumen, sedangkan umur dan jenis kelamin terbukti memiliki korelasi. Perempuan dan pelanggan muda lebih puas dengan paket spa yang ditawarkan oleh GY Spa.
\end{abstract}

Kata kunci: spa, demografi konsumen, kepuasan layanan 


\section{PENDAHULUAN}

Sebagai salah satu sektor andalan, pariwisata diharapkan dapat mendorong peningkatan devisa negara melalui arus kunjungan wisatawan dari mancanegara yang membelanjakan pendapatannya di Indonesia. Salah satu kecenderungan yang berkembang saat ini adalah atraksi/daya tarik wisata yang berkaitan dengan pemeliharaan kesehatan dan kebugaran seperti Spa. Spa adalah salah satu produk pariwisata yang saat ini sedang berkembang keras di Indonesia dan memiliki daya tarik dan keunikan tersendiri yang berbeda dengan spa-spa yang ada di negara lainnya, karena itulah, spa di Indonesia mempunyai keunggulan dan sangat bisa berkompetisi di forum Internasional. Saat ini banyak hotel dan biro perjalanan yang membuat paket perawatan spa.

Menyangkut perkembangannya, spa berkaitan erat dengan bathing (mandi), dan tentu saja dengan materi yang digunakan yaitu air. Sejak jaman purba, air merupakan elemen yang sangat vital bagi eksistensi dan perkembangan peradaban manusia. Segala pertumbuhan di dunia ini, sangat tergantung dengan kehadiran air. Dari jaman ke jaman, manusia memanfaatkan air sebagai kekuatan yang luar biasa untuk mencegah berbagai macam penyakit dan menjadi sarana kesehatan atau disebut dengan istilah hydrotherapy, .berasal dari bahasa Yunani, Hydor (air) dan Therapeia (penyembuhan). (Majalah Travel Club, Spa, antara Kebugaran, GY Hidup, dan Rekreasi, edisi Januari, 2004).

Di Indonesia, sejak zaman dahulu, kegiatan mandi-mandi ini, sebenarnya, juga sudah dilakukan oleh para bangsawan keraton, dengan mandi bunga/rempah, perawatan kecantikan luar dan dalam, luluran, ratus, masker bengkoang, dan lain-lain. Perawatan tradisional yang bersifat holistik dan menggunakan ramuan tumbuh-tumbuhan ini telah menjadikan para bangsawan keraton berpenampilan apik, penuh percaya diri, sehingga beda dengan rakyat biasa. Pada saat ini, spa menjadi pusat kesehatan dan tempat mengolah kesehatan pikiran, badan, dan spiritual. Orang pergi ke spa karena ingin melepaskan segala ketegangan pikiran, mendamaikan pikiran, bersantai, GY hidup sehat, dan bugar. Spa yang menggabungkan hal-hal tradisional dan teknik modern, GY Timur dan Barat, sejauh ini, telah memuaskan banyak pelanggan dari berbagai macam kalangan.

Menurut Mooryati Soedibyo, Ketua ASPI, Spa di Indonesia memiliki tren perkembangan yang bagus dari tahun ke tahun, yang sebelum tahun 2000 terdapat kurang dari 400 spa, antara 2001 - 2002 terdapat sekitar 500 spa, tahun 2003 terdapat 700 spa, tahun 2004 terdapat lebih dari 900 spa. Pada tahun 2006, pertumbuhan usaha spa di Indonesia mencapai 15\%. Pertumbuhan yang pesat ini tidak hanya terjadi di Indonesia, namun juga di negara-negara lainnya seperti Jepang, Australia dan Amerika Serikat. Peluang bisnis spa di Indonesia sangat terbuka lebar, karena Indonesia memiliki keunggulan-keunggulan, seperti: dari segi perawatan, interior dan eksterior, segi alam, segi produk, dan sumber daya manusia. Saat ini banyak terjadi permintaan tenaga spa therapist Indonesia dari mancanegara, karena tenaga terapis Indonesia sangat terkenal dengan compassionate service inclination-nya, sehingga sentuhan tangan Indonesia sangat berbeda dengan sentuhan orang dari bangsa lain.

Salah satu, yang menangkap peluang tersebut adalah PT. IGS, yang membuka jaringan day spa, di Jakarta, Bali, Kuala Lumpur, dan Pulau Penang Malaysia, di gedung milik sendiri maupun di hotel-hotel. Selain itu, GY Spa juga menyediakan produk-produk spa dan juga pendidikan terapist. Seperti halnya perusahaan lain yang berorientasi laba, maka GY Spa, tentu saja,harus dikelola secara profesional. Perbaikan-perbaikan yang berkesinambungan, baik secara internal maupun eksternal harus selalu dilaksanakan. Terlebih dengan semakin merebaknya para pemain di dalam bisnis tersebut, maka persaingan semakin tajam. Sementara umum diterima bahwa siapa yang lebih memahami permasalahan akan memiliki peluang survive yang lebih besar. 
Banyak aspek mendesak yang harus dipahami oleh manajemen spa, di antaranya adalah: bagaimana peta persaingan dalam bisnis spa, siapa kompetitor-kompetitornya, bagaimana kelebihankelebihan dan kekurangan-kekurangan dari para kompetitor, ketepatan dalam mensegmentasi konsumennya, apakah bauran pemasaran saat ini sudah dapat menjangkau segmen pasar yang dituju, dan tentu saja, apakah konsumen puas dengan produk/pelayanan GY Spa, dan sebagainya.

Ritual spa sudah dikenal bangsa Romawi lebih dari 2.000 tahun yang lalu. Tahun 25 SM, raja Agrippa membangun Roman Thermae pertama, yang merupakan sebuah spa skala besar pertama yang dikenal peradaban manusia. Thermae dilengkapi dengan pusat hiburan seperti pusat olah raga, restoran, dan berbagai macam bentuk perawatan tubuh. Pengunjung Thermae menjalani rutinitas seperti yang dilakukan di spa-spa modern, seperti berolahraga, sauna, berendam, pijat dengan minyak rempah, scrubing, kemudian diakhiri dengan relaksasi di perpustakaan.

Holloway (2009, p. 214) mengatakan bahwa spa merupakan salah satu elemen penting dalam wisata kesehatan. Istilah spa sendiri disebutkan berasal dari kota Spa di Belgia, walaupun sebagian menganggap bahwa istilah spa adalah "Sanitas Per Aqua" atau sehat melalui air (health through water). Sedangkan menurut Cook et al (2010, p. 237), arti spa adalah "mineral spring”. Namun penggunaan istilah ini berkembang menjadi sebuah tempat di mana orang-orang pergi untuk menyegarkan tubuh dan pikiran.

Spa dapat dibagi berdasarkan berdasarkan karakter, sebagai berikut (1) Spa Salon, Day Spa, atau City Spa. Spa yang tidak menyediakan akomodasi dan biasanya terletak di dalam kota untuk memberikan perawatan tubuh satu hari; (2) Resort Spa. Spa yang terletak di tengah alam, biasanya menyediakan akomodasi dan dipergunakan untuk para pengunjung yang ingin bersantai beberapa hari; (3) Destination Spa. Spa yang memberikan perawatan dan terapi untuk tujuan-tujuan tertentu dari sang pasien. Misalnya, ada yang ingin mengecilkan perut atau menurunkan berat badan; (4) Cruise Spa. Spa yang terdapat di kapal-kapal pesiar; (5) Medical Spa. Spa yang bekerja sama dengan rumah sakit. Biasanya, spa ini memberikan terapi-terapi untuk orang-orang yang habis operasi atau kecelakaan. Biasanya, peralatan untuk medical spa akan lebih modern dibandingkandengan spa jenis lain; (6) Club Spa. Spa yang khusus untuk para member-nya saja.

Pada saat ini, banyak hotel-hotel maupun industry hospitality lainnya yang menjadikan spa sebagai salah satu fasilitas kesehatan dan tempat mengolah kesehatan pikiran dan badan. Di Indonesia sendiri, bisnis Spa yang umum ditemui adalah day spa, destination spa, resort spa, Hotel Spa dan lain sebagainya. Dengan semakin menjamurnya bisnis spa di Indonesia, maka pengelola bisnis spa harus memperhatikan keinginan dan kebutuhan konsumen agar tercipta kepuasan konsumen, yang merupakan persyaratan untuk terciptanya loyalitas pelanggan. Menurut Kotler et al (2006, p. 396), kepuasan konsumen mengukur bagaimana harapan-harapan konsumen dapat terpenuhi. Bila kinerja lebih kecil dari harapan, maka konsumen tidak akan merasa puas, bila kinerjasama dengan harapan, maka konsumen akan merasa puas, dan jika kinerja lebih besar dari harapan, maka konsumen akan merasa amat puas atau senang.

Kotler (2000) mengemukakan empat metode untuk mengukur kepuasan konsumen. Keempat metode tersebut adalah sistem keluhan dan saran (complaint and suggestion systems), survey kepuasan konsumen (customer satisfaction surveys), belanja siluman (ghost shopping) dan analisis kehilangan pelanggan (lost customer analysis). Pasar terdiri dari para pembeli yang memiliki karakteristik yang berbeda. Melalui segmentasi pasar, perusahaan membagi pasar yang besar dan heterogen ke dalam segmen-segmen yang kecil, sehingga dapat dijangkau oleh perusahaan secara lebih efisien dan efektif, dengan produk dan jasa yang sesuai dengan kebutuhan konsumen dalam segmen tersebut.

Tidak ada cara yang baku untuk mensegmen sebuah pasar. Seorang pemasar harus mencoba menggunakan variabel segmentasi yang berbeda-beda, baik dengan satu variabel saja maupun dengan mengkombinasikan variabel-variabel tersebut, untuk mencari cara terbaik memandang struktur pasar. 
Menurut Kotler et al (2006), segmentasi pasar dapat dibagi menjadi sebagai berikut (1) Segmentasi geografis, yaitu membagi pasar menjadi unit-unit geografis yang berbeda-beda, seperti wilayah, ukuran kota, kepadatan, atau cuaca; (2) Segmentasi demografis, yaitu membagi pasar menjadi sejumlah kelompok berdasarkan usia, jenis kelamin, ukuran keluarga, siklus hidup keluarga, pendapatan, pekerjaan, pendidikan, agama, ras, dan kebangsaan; (3) Segmentasi psikografis, yaitu membagi pasar menjadi kelompok-kelompok yang berbeda berdasarkan kelas sosial, GY hidup, dan kepribadian; (4) Segmentasi perilaku, yaitu membagi pasar ke dalam sejumlah kelompok berdasarkan kegunaan, manfaat, status pengguna, jenis pengguna, loyalitas, tahap kesiapan dan sikap terhadap produk.

Dalam penulisan ini, hanya akan dibahas segmentasi pasar dari aspek demografi yang mencakup lima kelompok, yaitu dari aspek kewarganegaraan, jenis kelamin, usia, pendidikan dan pekerjaan. Pada penulisan ini ingin diketahui hubungan antara demografi konsumen (kewarganegaraan, jenis kelamin, usia, pendidikan, dan pekerjaan) dengan kepuasan konsumen terhadap layanan paket perawatan spadi GY Spa.

\section{METODE PENELITIAN}

Unit analisis di dalam penelitian ini adalah individu pria dan wanita sebagai konsumen yang pernah menikmati layanan di GY Spa. Adapun variabel-variabel yang diukur terdiri dari 2 variabel, yaitu variabel demografi dan variabel kepuasan.

Tabel 1 Variabel Penelitian

\begin{tabular}{|c|c|c|c|}
\hline No. & Variabel & Sub Variabel/Indikator & $\begin{array}{c}\text { Skala } \\
\text { Pengukuran }\end{array}$ \\
\hline 1. & Demografi & $\begin{array}{ll}\text { - } & \text { Kewarganegaraan } \\
\text { - } & \text { Jenis Kelamin } \\
\text { - } & \text { Usia } \\
\text { - } & \text { Pendidikan } \\
\text { - } & \text { Pekerjaan }\end{array}$ & $\begin{array}{l}\text { Nominal } \\
\text { Nominal } \\
\text { Ordinal } \\
\text { Ordinal } \\
\text { Nominal }\end{array}$ \\
\hline 2. & $\begin{array}{l}\text { Kepuasan Layanan Paket } \\
\text { Perawatan Spa }\end{array}$ & $\begin{array}{l}\text { - } \quad \text { Massage Traditional } \\
\text { - } \quad \text { Paket Nirwana } \\
\text { - } \quad \text { Paket Spa } \\
\text { - } \quad \text { Paket Spa secara Umum }\end{array}$ & $\begin{array}{l}\text { Likert } \\
\text { Likert } \\
\text { Likert } \\
\text { Likert }\end{array}$ \\
\hline
\end{tabular}

Penulis memakai instrument skala Likert dalam melakukan penelitian kepuasan konsumen GY Spa. Menurut Sugiyono (1997) skala Likert ini digunakan untuk mengukur sikap, pendapat, dan persepsi seseorang atau sekelompok orang tentang fenomena sosial. Dengan skala Likert, maka variabel yang akan diukur dijabarkan menjadi variabel indikator. Kemudian, variabel indikator tersebut dijadikan sebagai titik tolak untuk menyusun item-item yang dapat berupa pertanyaan atau pernyataan. Alasan penulis untuk memakai skala ini adalah agar responden dapat dengan mudah menunjukkan pada skala berapa mereka menyatakan sangat tidak memuaskan sampai dengan sangat memuaskan.

Dalam penelitian ini, para responden diminta untuk memberikan penilaian terhadap layananlayanan di GY Spa, dengan 5 alternatif jawaban sebagai berikut (1) Sangat Tidak Memuaskan, dengan skor = 1; (2) Tidak Memuaskan, dengan skor = 2; (3) Biasa-biasa, dengan skor = 3; (4) Memuaskan, dengan skor $=4$; dan (5) Sangat Memuaskan $\quad$, dengan skor $=5$. 
Karena jumlah populasi tidak diketahui dan responden yang datang tidak dapat diprediksi, kapan dan siapa, maka metode sampling yang digunakan dalam penulisan ini adalah accidental sampling, di mana proses pengambilan sampel dilakukan tanpa perencanaan yang seksama. Responden yang dimintai informasi benar-benar dilakukan secara kebetulan tanpa suatu pertimbangan tertentu. Dengan menggunakan metode ini, responden ditentukan secara kebetulan. Data yang diperoleh dari konsumen melalui kuesioner merupakan data primer, didukung oleh data sekunder. Untuk mengetahui hubungan antara demografi konsume dengan kepuasan terhadap layanan paket perawatan spa di GY Spa digunakan statistik Chi Square. Chi Square adalah statistik untuk menguji independensi. Chi Square digunakan untuk menguji apakah 2 variabel tidak saling berhubungan. Dalam penelitian ini, variabel yang ingin diuji adalah demografi konsumen dengan kepuasan terhadap layanan paket perawatan spa. Adapun penelitian dilakukan pada bulan Juli sampai dengan Agustus 2006.

\section{HASIL DAN PEMBAHASAN}

Kuesioner dibagikan kepada 100 responden dan yang terkumpul kembali dan dapat digunakan untuk penelitian adalah 92 lembar. Berikut adalah demografi konsumen yang diperoleh dari pengumpulan data melalui penyebaran kuesioner. Pertama, kewarganegaraan konsumen. Sebagian besar konsumen GY Spa adalah warga negara Indonesia sebesar 92,4\%, dan sisanya sebesar 7,6\% adalah warga negara asing dari Belanda, Cina, Inggris, Irlandia, Jepang. Kedua, jenis kelamin konsumen. Dari total responden, konsumen wanita lebih besar daripada pria yaitu sebanyak $60.9 \%$ dan pria sebanyak $39.1 \%$.

Ketiga, usia konsumen. Usia konsumen terbesar berkisar antara 20 - 30 tahun (56,2\%), disusul dengan usia 31 - 40 tahun (27\%), dan kurang dari 20 tahun (10,1\%), kemudian usia $41-50$ tahun (5,6\%) dan yang terakhir adalah usia $51-60$ tahun (1.1\%). Hal ini terjadi, diduga, karena usia 20 - 30 tahun adalah usia muda yang produktif, di mana mereka memiliki penghasilan sendiri, belum berkeluarga, memiliki kebutuhan untuk mencoba sesuatu yang baru, berpenampilan menarik, dan menikmati kehidupannya. Tentu saja, berkunjung ke spa adalah salah satu alternatif yang mengena dan rasional untuk mereka.

Keempat, pendidikan terakhir konsumen. Dari 92 orang yang merespon kuesioner, delapan orang tidak memberikan jawaban, 84 orang menjawab pertanyaan tentang pendidikan terakhir, dan diperoleh distribusi sebagai berikut:konsumen terbanyak berpendidikan Diploma/S1 (73,8\%), disusul dengan S2 (15,5\%), sampai dari SMU (sederajat) (9,5\%), dan yang terakhir adalah pendidikan S3 (1,2\%). Hal ini terjadi, diduga, karena orang-orang berpendidikan Diploma/S1, lebih terpelajar daripada lulusan SMU, namun belum memiliki kebutuhan sebanyak lulusan S2 ataupun S3. Sehingga, mereka memiliki lebih banyak uang lebih untuk memenuhi kebutuhan sekunder.

Kelima, pekerjaan konsumen. Kebanyakan konsumen konsumen adalah karyawan (33,7\%) dan mahasiswa $(27,2 \%)$ dan wiraswasta $(26,1 \%)$. Kemudian, ibu rumah tangga $(7,6 \%)$, PNS $(3,3 \%)$ serta guru dan pensiunan masing-masing $1,1 \%$. Hal ini terjadi, diduga karena karyawan di Jakarta mengalami tekanan kerja yang relatif tinggi sehingga mereka lebih membutuhkan suasana, waktu, dan tempat untuk relaksasi untuk menghilangkan kepenatan dan kejenuhan sehari-hari yang mereka alami di tempat kerja. Spa tentu saja adalah alternatif yang baik untuk mereka. Selain itu, karyawan memiliki penghasilan yang lebih banyak dibandingkan pekerjaan yang lain seperti guru, ibu rumah tangga, pensiunan, dan PNS. Sementara, mahasiswa dengan usia yang kebanyakan muda cenderung membutuhkan penampilan yang lebih menarik/cantik, dan cenderung mencoba hal yang baru bersama sahabat-sahabat mereka. 
Terdapat 4 paket layanan perawatan spa yang ditawarkan oleh GY Spa, yaitu massage traditional Indonesia 90 menit, paket nirwana GY 120 menit (body scrub, body massage, dan face massage), paket spa GY 150 menit (body scrub, arometherapy herbal/salt bath, dan body massage) dan GY Spa secara umum. Berdasarkan Tabel 2, dapat dilihat bahwa tidak ada hubungan antara kewarganegaraan, pendidikan dan pekerjaan terhadap kepuasan layanan dari keempat paket perawatan. Sedangkan bila ditinjau dari jenis kelamin, konsumen wanita lebih puas terhadap layanan yang diberikan oleh masing-masing paket perawatan. Faktor usia juga mempengaruhi tingkat kepuasan terhadap layanan, semakin muda usia konsumen, semakin puas terhadap layanan perawatan.

Tabel 2 Hubungan antara Demografi Konsumen dengan Kepuasan terhadap Layanan Paket Perawatan Spa yang Ditawarkan oleh GY Spa

\begin{tabular}{|c|c|c|c|c|}
\hline Karakteristik & $\begin{array}{c}\text { Massage } \\
\text { Tradisional }\end{array}$ & Paket Nirwana GY & $\begin{array}{c}\text { Paket } \\
\text { Spa GY }\end{array}$ & $\begin{array}{c}\text { GY Spa } \\
\text { Secara Umum }\end{array}$ \\
\hline $\begin{array}{l}\text { Kewarga } \\
\text { Negaraan }\end{array}$ & $\begin{array}{l}\text { Tidak ada } \\
\text { hubungan }\end{array}$ & Tidak ada hubungan & Tidak ada hubungan & Tidak ada hubungan \\
\hline Pendidikan & $\begin{array}{l}\text { Tidak ada } \\
\text { hubungan }\end{array}$ & Tidak ada hubungan & Tidak ada hubungan & Tidak ada hubungan \\
\hline Pekerjaan & $\begin{array}{l}\text { Tidak ada } \\
\text { hubungan }\end{array}$ & Tidak ada hubungan & Tidak ada hubungan & Tidak ada hubungan \\
\hline Jenis Kelamin & $\begin{array}{l}\text { Ada hubungan } \\
\text { Wanita lebih puas } \\
\text { dari pria }\end{array}$ & $\begin{array}{l}\text { Ada hubungan } \\
\text { Wanita lebih puas dari } \\
\text { pria }\end{array}$ & $\begin{array}{l}\text { Ada hubungan } \\
\text { Wanita lebih puas } \\
\text { dari pria }\end{array}$ & $\begin{array}{l}\text { Ada hubungan } \\
\text { Wanita lebih puas dari } \\
\text { pria }\end{array}$ \\
\hline Usia & $\begin{array}{l}\text { Ada hubungan } \\
\text { Usia muda lebih } \\
\text { puas dari usia tua }\end{array}$ & $\begin{array}{l}\text { Ada hubungan } \\
\text { Usia muda lebih puas } \\
\text { dari usia tua }\end{array}$ & $\begin{array}{l}\text { Ada hubungan } \\
\text { Usia muda lebih } \\
\text { puas dari usia tua }\end{array}$ & $\begin{array}{l}\text { Ada hubungan } \\
\text { Usia muda lebih puas } \\
\text { dari usia tua }\end{array}$ \\
\hline
\end{tabular}

\section{SIMPULAN}

Berdasarkan faktor demograpfi yang terdiri atas kewarganegaraan, pendidikan dan pekerjaan, diketahui bahwa tidak ada hubungan antara ketiga faktor tersebut terhadap kepuasan layanan paket perawatan spa yang ditawarkan oleh GY Spa, sedangkan jenis kelamin dan usia memiliki hubungan dengan kepuasan layanan. Konsumen wanita dan konsumen yang berusia muda lebih puas terhadap layanan paket perawatan spa. Menimbang bahwa masih terbatasnya ruang lingkup penelitian ini, maka masih dapat dikembangkan penelitian lebih lanjut terhadap aspek demografi maupun geografi, psikografi, dan perilaku. Saran yang bisa diberikan dalam penelitian ini adalah GY Spa perlu menciptakan paket perawatan yang berbeda antara konsumen wanita dan pria, agar GY Spa dapat menarik lebih banyak konsumen pria. Selain itu, GY Spa perlu memperhatikan paket perawatan yang dinikmati oleh konsumen usia tua, sehingga GY Spa dapat memberikan penawaran paket perawatan yang menarik konsumen dari berbagai usia. 


\section{DAFTAR PUSTAKA}

Anonim. (2004). Spa, antara kebugaran, GY hidup, dan rekreasi. Majalah Travel Club, edisi Januari.

Anonim. (2009). Bisnis pariwisata: Tata bisnis spa. Diakses dari http://pedulipariwisata.blogspot.com/2009/08/tata-bisnis-spa.html.

Anonim. (2010). Lembaga sertifikasi profesi spa. Diakses tanggal 20 September, 2010, dari http://www.lsp-spa-nasional.org/

Cook, R.A., Yale, L.J., and Marqua, J.J. (2010). Tourism: The business of travel, $4^{\text {th }}$ ed., New Jersey: Pearson Education Inc.

Holloway, J.C, et al. (2009). The business of tourism, $8^{\text {th }}$ ed., Essex: Pearson Education Ltd.

Kotler, P. (2000). Marketing management, New Jersey: Prentice Hall.

Kotler, P., Bowen, J.T., and Maken, J.A. (2006). Marketing for hospitality and tourism, $4^{\text {th }}$ ed., New Jersey: Pearson International Education.

Sugiyono. (1997). Statistika untuk penelitian, Bandung: Alfabeta. 